\title{
Two foreign bodies embedded in the intraventricular septum: a case report
}

\author{
Sotirios Moraitis1, Apostolos Perelas1, Panagiotis Hountis1, Dimitrios Moraitis2, \\ Maria Chounti3 , Eirini Rogdaki4
}

\author{
1 Department of Thoracic Surgery, Athens Naval and Veterans Hospital, 70 Dinokratous Str., Kolonaki, \\ 11255 Athens \\ 2 Department of Administration and Statistics, Athens Naval and Veterans Hospital, Deinokratous 70, \\ 11521 Athens \\ 3 Nursing School, Technological Institute of Patra, Megalou Alexandrou 1, Koukouli, 26334 Patra \\ 4 Radiology Department, Kyanous Stauros Hospital, 102 Vasilissis Sofias Str., 11528 Athens, Greece
}

\begin{abstract}
A 23-year old male was presented at the outpatient clinic of our department reporting that he had been subjected to insertion of foreign bodies in his chest. Physical examination was unremarkable. Imaging studies revealed the presence of two bodies in the subcutaneous tissue of the anterior chest wall and two needle-shaped intramyocardial bodies that were impacted in the intraventricular septum. Due to late appearance, the position, and because of the absence of symptoms, it was decided that the patient should be managed conservatively. Today, five years after the incident, the patient remains asymptomatic and he is followed-up regularly.
\end{abstract}

\section{Introduction}

Intracardiac foreign bodies are a rare indication for cardiac surgery. These are usually the result of accidents such as sewing needles, acupuncture needles and saw fragments. Also, they can result from self-mutilation (suicide attempts, schizophrenia), or from firearm injuries (gunshots, grenade fragments). In addition, they may result from abuse or intravenous drug administration, as well as

Corresponding author: Panagiotis Hountis, Department of Thoracic Surgery, Athens Naval and Veterans Hospital, 70 Dinokratous Str., Kolonaki, 11255 Athens, Greece. Tel. +30.6986004089 - Fax: +30.210.2133437.

E-mail: panos_hountis@hotmail.com

Key words: Computed tomography; foreign body; right ventricle; left ventricle; penetrating trauma.

Received for publication: 13 September 2016

Accepted for publication: 17 October 2016

CC Copyright S. Moraitis et al., 2017

Tipografia PI-ME Editrice, Italy

Monaldi Archives for Chest Disease 2017; 87:776

doi: 10.4081/monaldi.2017.776

This article is distributed under the terms of the Creative Commons Attribution Noncommercial License (by-nc 4.0) which permits any noncommercial use, distribution, and reproduction in any medium, provided the original author(s) and source are credited. from medical procedures (catheter fragments, pacemaker wire fragments, valvulotomy rings) [1].Foreign body injury in the heart, has been usually associated with dramatic clinical picture of the patient, such as thoracic pain, dyspnea, pericardial effusion, pneumothorax, pleural pain, cardiac tamponade and/or bleeding and cardiac arrest [2]. We present herein the rare case of a completely asymptomatic young male who was diagnosed with intracardiac foreign body. The real circumstances of this strange event were never fully delineated.

\section{Case Report}

A 23-year old man presented at the outpatient clinic of the Thoracic Surgery Department of the Naval and Veterans Hospital of Athens, reporting that he had been injured in the chest, 3 months ago. The patient refused to provide any information regarding the circumstances under which the incident took place, or the nature of the inserted objects. He was admitted in the Thoracic Surgery Department for evaluation. On presentation, the patient was completely asymptomatic, and the physical examination was unremarkable. No penetration wounds were noted on his chest wall. Imaging studies with chest X-rays, contrast computed tomography with 3D reconstruction (Figures 1 and 2), and computerized coronary angiography revealed 2 metallic foreign bodies in the subcutaneous tissue of the anterior chest wall and an intracardiac needleshaped foreign body that seemed to have been broken in two pieces. The smaller part, with an approximate length of $3.2 \mathrm{~cm}$ penetrated the free wall of the right ventricle and was impacted in the intraventricular septum. The larger part, approximately $5.7 \mathrm{~cm}$ in length, was found behind and in line with the aforementioned part and was impacted in the intraventricular septum penetrating the posterior wall of the left ventricle and the papillary muscle, with its posterior edge impacted in the apex of the heart. Ultrasonographic studies revealed, a normal heart anatomy and ventricular contractility (ejection fraction: 55\%), also normal valve functioning and absence of pericardial effusion. Psychiatric evaluation found the patient to be suffering from depression and he was placed under antidepressant therapy. Due to late appearance and the position of the foreign bodies, it was decided that the patient should not undergo immediate surgical intervention, but rather he should receive antiplatelet treatment (acetylsalicylic acid $100 \mathrm{mg}$ per day) and reassessed 3 and 6 months after the initial presentation for signs necessitating invasive treatment. During these follow-up visits, the position of the foreign bodies remained unchanged and the patient has remained completely asymptomatic and in excellent condition. Regular follow-up (clinical examination, chest X-rays, ultrasonography and rest electrocardiogram) is conducted on a six-month basis. 


\section{Discussion}

Symptomatic cardiac foreign bodies are usually managed emergently and they are removed. In general, treatment options include surgery to remove the foreign body or a conservative approach, based on the symptoms of the patient, the location of the foreign body, and the time between the injury and the presentation. When they do not cause symptoms, their proper management is still debated. Some advocate that they are usually entrapped by fibrous tissue and do not cause particular harm [3]. Although recurrent endocarditis, intramural hematoma, arrhythmia and valve incompetence have been reported in some patients [4]. When intracardiac foreign bodies represent incidental finding it is imperative to determine its anatomic association with adjacent structure. Symptomatic patients (cardiac tamponade, bleeding, fever, pericarditis, pericardial effusion, peripheral embolization, arrhythmia, thrombi, neurotic manifestations, pneumothorax) are managed operatively [5]. On the other hand, the management of asymptomatic patients depends on the nature and location of the foreign body. Also, intraoperative imaging studies are important to demonstrate migration of the foreign body even during the patient positioning. Transesophageal echocardiography may help identify foreign bodies into the cardiac muscle. Patients with the foreign bodies completely embedded in the myocardium or in the pericardial space usually remain symptom-free for a time. Symbas et al. [6] suggest that these foreign bodies could be left in place. On the other hand, intracavitary bodies or bodies partially embedded in the myocardium, especially in the left side of the heart should be removed because of the risk of infection or embolization. In our case, the needle was completely embedded in the septum (Figure 1 and 2). According to our findings we chose a conservative approach, having in mind that the patient had already survived the condition that caused the foreign body impaction. One of our major concerns was whether to place the patient under antiplatelet and/or anticoagulant treatment, a matter that has not been adequately addressed by the current literature. We chose low-dose acetylsalicylic acid, as the most suitable therapy between using aggressive anticoagulation with warfarin and neither anticoagulation at all. Today, five years after the incident, the patient remains asymptomatic. He is reassessed biannually with plain chest Xrays, rest electrocardiogram and ultrasonography and continues the antiplatelet without adverse effects.

\section{Conclusions}

This is an extraordinary case presentation in which a young male was presented with foreign bodies (wires) embedded in his heart and lung. We believe that he survived a process that could have killed him. He presented late in the course and we followed a conservative approach. Until now he is completely asymptomatic and it seems that this approach is justified.

\section{References}

1. Talwar S, Subramaniam KG, Subramanian A, et al. Sewing needle in the heart. Asian Cardiovasc. Thorac. Ann. 2006;14:63-5.

2. Actis Dato GM, Arslanian A, Di Marzio P, et al. Posttraumatic and iatrogenic foreign bodies in the heart: report of fourteen cases and review of the literature. J. Thorac. Cardiovasc. Surg. 2003; 126:408-14.

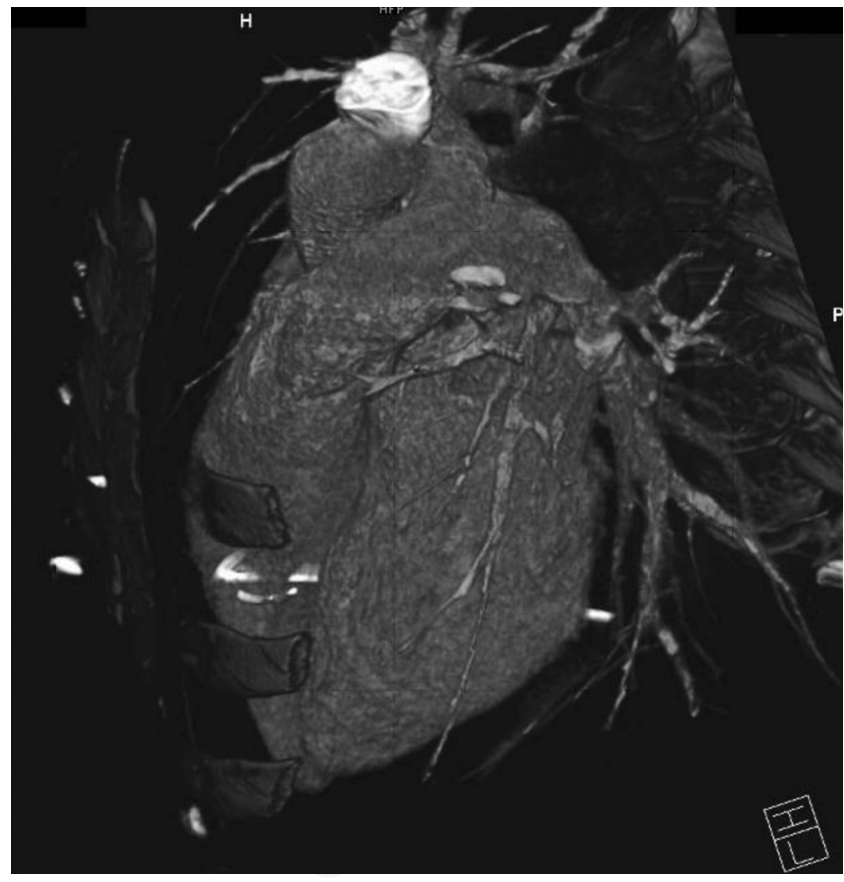

Figure 1. CT Angiography with $3 \mathrm{D}$ reconstruction showing the needle crossing the intraventricular septum (lateral view of the heart).

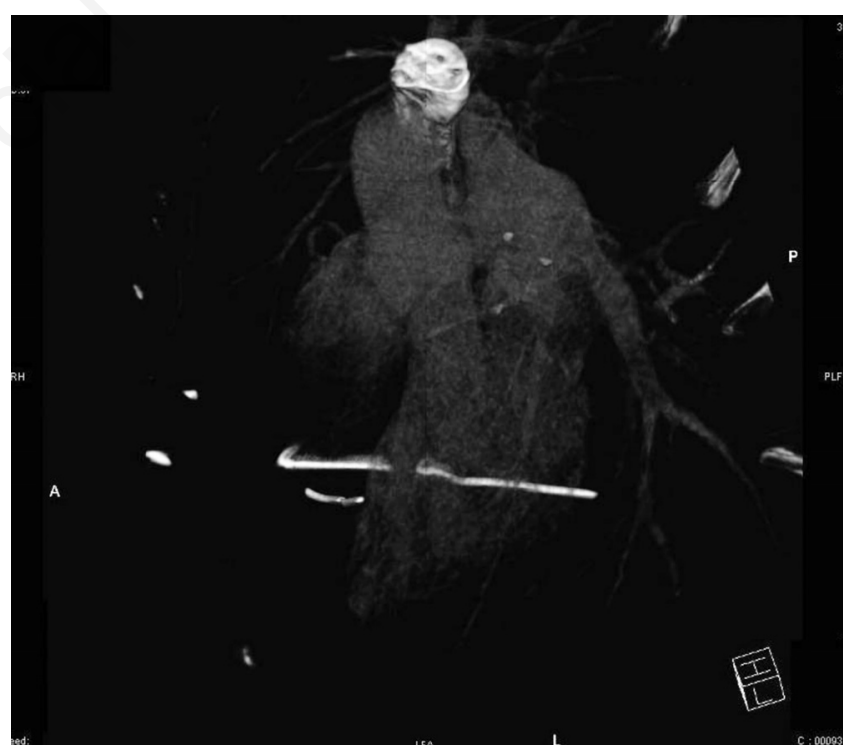

Figure 2. The lateral view of the heart after the substracting of the heart silhouette.

3. Jamilla FP, Casey LC. Self-inflicted intramyocardial injury with a sewing needle: a rare cause of pneumothorax. Chest 1998;113:531-4.

4. Kobayashi T, Hayashi K, Sakata K, Kobayashi Y. Tricuspid valve incompetence caused by an intracardiac needle-like foreign body. Ann. Thorac. Surg. 2005;80:322-4.

5. Ono M, Wolf RK. Heart injury and endocarditis caused by a needle migrated from the left arm. Eur. J. Cardiothorac. Surg. 2001;20:1074.

6. Symbas PN, Symbas PJ. Missiles in the cardiovascular system. Chest Surg. Clin. N. Am. 1997;7:343-56. 